\title{
Phenotype management: a new approach to habitat restoration
}

\author{
Jason V. Watters Sean C. Lema Gabrielle A. Nevitt
}

\begin{abstract}
The goal of habitat restoration is to provide environmental conditions that promote the maintenance and growth of target populations. But rarely is it considered how the allocation of resources influences the diversity of phenotypes in these populations. Here we present a framework for considering how habitat restoration can shape the development and expression of phenotypes. We call this approach phenotype management as it entails restoring the resources in a habitat to manage phenotypic diversity. Phenotype management is achieved by manipulating the spatial and temporal distribution of resources to alter the degree of competition among individuals. Differences in competition, in turn, lead to changes in phenotypic and life history expression that affect population parameters including demography and effective population size $\left(N_{\mathrm{e}}\right)$. To illustrate how phenotype management can be applied, we explore how resource distributions shape variation in phenotypes in two imperiled fishes, Pacific salmon and desert pupfish. In both examples, modulating male reproductive phenotypes changes the allocation of reproductive success among population members to subsequently affect $N_{\mathrm{e}}$. These examples further demonstrate that whether to increase or decrease phenotypic diversity depends on the primary conservation pressures faced by the species.
\end{abstract}

Keywords: Resource distribution; Habitat complexity; Population viability; Salmon; Pupfish

\section{Introduction}

The physical alteration of aquatic habitats is a primary cause for the decline of native fish populations (e.g. Neves and Angermeier, 1990; Moyle, 1994). Examples of affected species are numerous, ranging from commercially important species such as Pacific salmon (for review, see Levin and Schiewe, 2001) to desert pupfishes (Minckley and Deacon, 1991) and other lesser known natives (e.g. Modoc sucker, Catostomus microps, Moyle, 1976; Razorback sucker, Xyrauchen texanus, Minckley et al., 1991a; Colorado pikeminnow, Ptychocheilus lucius, Tyus, 1991; spotfin chub, Cyprinella monacha, Jenkins and Burkhead, 1984). Modifications for flood control, agriculture, and hydroelectric facilities are only a few examples of anthropogenic alterations that dramatically change the physical structure of aquatic habitats, resulting in the decline or extinction of native fishes. Such habitat modifications alter the quantity, quality, and distribution of resources that individuals in a population need for survival and reproduction.

Habitat restoration, in turn, aims to replenish these resources and preserve populations after anthropogenic environmental change. But what is the best way to engineer habitats to support self-sustaining populations? The goal of any restoration effort is to provide the environmental conditions that promote the maintenance and growth of the target population. Restoring fish habitat spans from replenishing substrate and shelter (by providing sand, gravel, boulders, logs) to modifying water flow. Project managers tend to decide on restoration plans by determining the minimum habitat structure required for successful spawning (e.g. Johnston, 1999), or by choosing to restore just those habitat types that support the highest density of individuals. For instance, habitat restoration for juvenile coho salmon (Oncorhynchus kisutch) often focuses on constructing pools (Flosi et al., 1998) because pools support the highest densities of juveniles. As a result, phenotypes that survive well in pools are favored. While we 
use this case as an example, it is rather typical for restoration efforts to be unintentionally tailored to only a subset of the population. These efforts are geared to increase populations quickly, but they may overlook other phenotypes that only develop in low-density habitats (Puckett and Dill, 1985; Nielsen, 1992). Because we rarely know which habitats are yielding fish that will eventually survive to reproduce, restoration efforts that are limited to constructing only a few types of habitat may be less effective at restoring species over the long-term.

In the simplest sense, the viability of a population depends on the ability of its members to survive and reproduce. This ability is impacted by phenotypic variation because different phenotypes approach the problems of survival and reproduction in different ways. Examples where variation in phenotypic expression occurs as a result of differences in resource distribution are common (e.g. Witte et al., 1990; Mittelbach et al., 1999; Skülason et al., 1999). Yet, restoration workers are rarely concerned with how changing the distribution and availability of resources affects the phenotypes expressed by a population. We suggest that restoration planners consider manipulating resources to explicitly manage the expression of phenotypes. We call this approach phenotype management.

Phenotype management is essentially a bet-hedging strategy that ensures the persistence of a population in the face of environmental uncertainty. Phenotype management can work in several ways. By promoting phenotypic variability, we can increase the probability that some individuals will survive drastic changes in the environment. One way to promote phenotypic variety is to create heterogeneous habitats because when habitats are variable, individuals use them in different ways. Thus, when environmental change alters specific components of the habitat, individuals are affected to different degrees and face different probabilities of surviving the changes that have been imposed. An obvious economic analogy is the prudent investor who builds a diversified portfolio to safeguard a capital investment against unpredictable change. Investing in a single stock, however, may offer the highest returns when the market is predictable. With respect to phenotypic management, the currency of those returns comes in the form of survivorship of individuals within a population. Whether or not to diversify the phenotypic portfolio will depend on the particular species in question and the predictability of the environment.

Here we illustrate a framework for managing phenotypic diversity to meet the specific goals of any habitat restoration project. To use phenotype management to restore native species, the effects of habitat manipulations on the expression of phenotypes must be considered. This approach requires integrative thinking across multiple disciplines, from developmental biology to ecology and population biology; the emphasis is as much on understanding processes as documenting outcomes.

\section{Phenotypic variation and population persistence}

As humans, we have the ability to rapidly alter environments. We can remove the forest canopy surrounding a stream in a matter of days, even though that same canopy took decades to become established. This alteration immediately increases the temperature and silt composition of the stream habitat. We dam even the largest rivers in only a few years, converting fast-flowing waterways into stagnant reservoirs and sluggish canals. These and other anthropogenic alterations rapidly transform the selective pressures on organisms, frequently within a single generation.

The range of phenotypic variation within a population plays a critical role in whether the population continues to persist in the face of these alterations, or is driven to extinction. When the environment changes, some phenotypes survive better than others (e.g. Boag and Grant, 1981). These initial effects of selection occur within a single generation. This idea is often referred to as "phenotypic selection" and does not require genetic variation (e.g. Endler, 1986). Because phenotypic selection removes those phenotypes that are poorly fit to the environment, the degree of phenotypic diversity in a population plays a role in whether that population persists in the face of environmental change. Even if this variation is not heritable, it is still an important component of a population's viability. For these reasons conservation biologists must consider how habitat shapes the expression of phenotypes, and avoid restoring habitats to support only a limited range of phenotypes.

Recent experimental evidence illustrates how variation in habitat shapes morphological (e.g. Cichlasoma managuense, Meyer, 1987; Gasterosteus aculeatus, Day et al., 1994), behavioral (e.g. Poecilia reticulata, Rodd and Sokolowski, 1995; Salmo salar, Metcalfe and Thorpe, 1992), and life history phenotypes (e.g. Poecilia latipinna, Trexler et al., 1990). Populations of the pumpkinseed sunfish, Lepomis gibbosus, for instance, exhibit significant variation in feeding morphology. In these fish, individuals from different populations can differ almost three-fold in the size of jaw muscles used for crushing hard prey (Mittelbach et al., 1992). The size of these muscles positively correlates with the availability of gastropods in a habitat, which is modified by the abundance and distribution of prey, as well as the degree of competition among sunfish. Yet these phenotypic differences disappear when pumpkinseeds from different populations are reared under identical environmental conditions. However, raising fish on 
either a diet with or without gastropods generates large differences in jaw morphology (Mittelbach et al., 1999). Thus, these phenotypic differences between pumpkinseed populations are a response to developing in environments where resources differ.

Because the distribution of resources in a habitat drives the expression of phenotypes, habitat restoration will directly affect the phenotypes seen in a population. For example, it is well established that when resources are clumped in space, some individuals can defend the resources thereby leading to unequal resource acquisition among individuals (Brown, 1964). In this case, variation in phenotypes is likely to occur as a result of either differential acquisition of resources (e.g. Ryer and Olla, 1995), or because individuals adopt alternative tactics to acquire those resources (e.g. Puckett and Dill,

\section{Broad Phenotype Distribution}
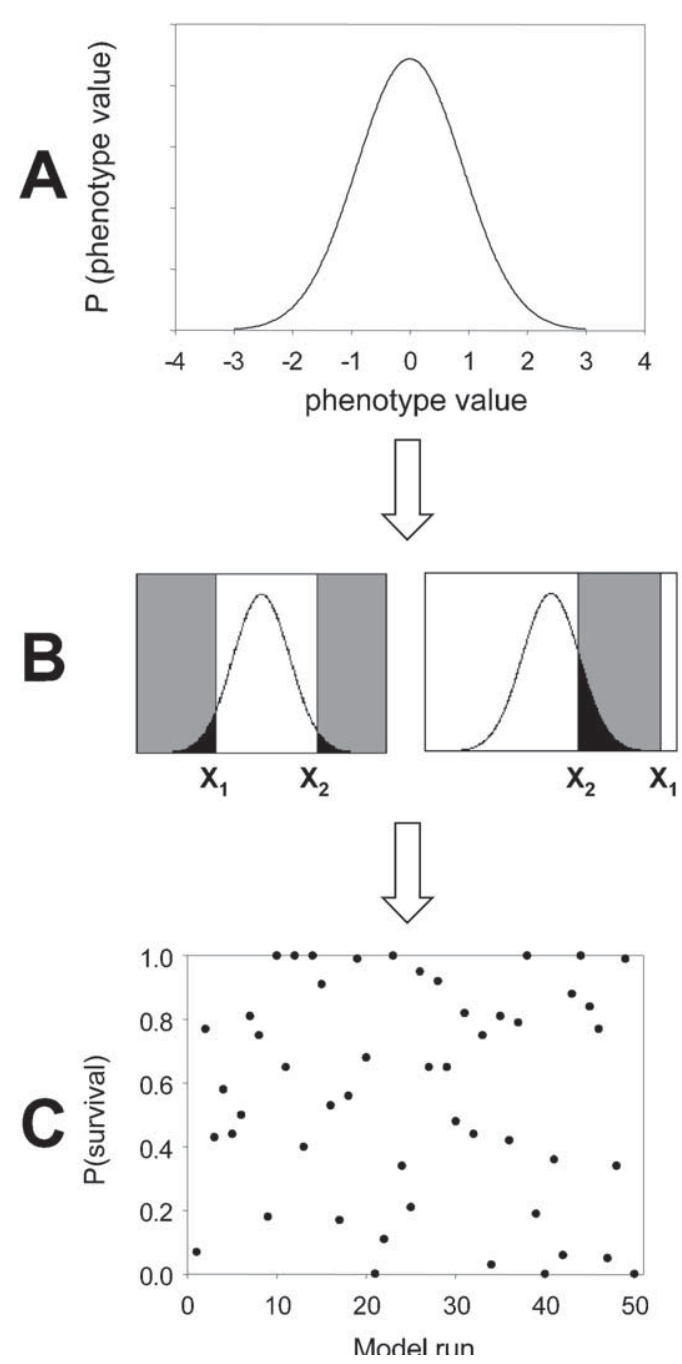

1985; MacLean et al., 2000). Conversely, when resources are evenly distributed, they are difficult for an individual to defend, and resource acquisition is likely to be similar among population members. Recent evidence also suggests that evenly distributed resources reduce phenotypic variation (e.g. Watters and Nevitt, unpublished data).

Given that variation in resources can generate phenotypic diversity, environmental changes that remove or limit this resource variation are likely to eliminate some phenotypes from a population. This idea is illustrated in Fig. 1. Here we have constructed a simple model that calculates the proportion of a population that is likely to survive an unpredictable environmental change. The underlying assumptions of our model are that (1) similar phenotypes use a habitat in similar ways and (2)

\section{Narrow Phenotype Distribution}
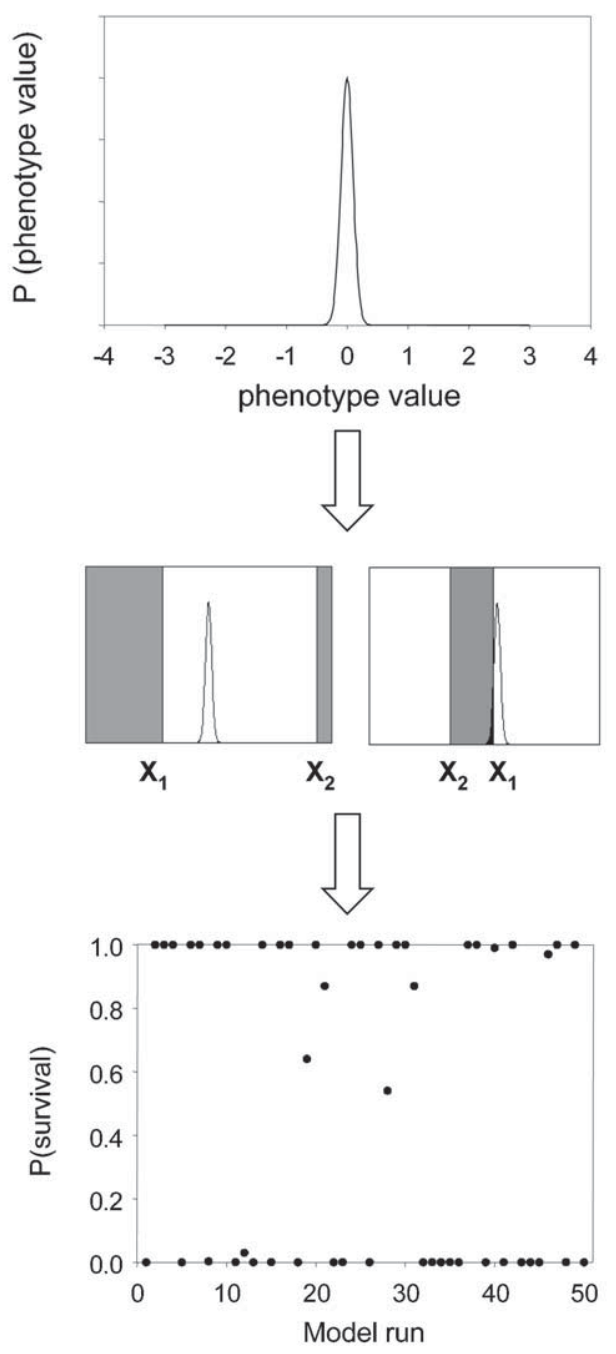

Fig. 1. Comparison of the response of populations with either a broad or a narrow phenotypic distribution (A) to stochastic environmental change. Change removes members from the standing population by restricting the phenotypes that can survive in the modified environment (B). In this model, the probability of a particular individual surviving is determined by the phenotypic boundaries, $x_{1}$ and $x_{2}$. The position of these boundaries is randomized in the model. Multiple runs of this model suggest that populations with a narrow phenotypic distribution are more likely to be forced to extinction, while populations with a broad phenotypic distribution are more likely to persist following a random change in selective pressures (C). 
dissimilar phenotypes will use a habitat, or its components, in dissimilar ways. The model imposes random environmental changes that eliminate some phenotypes from the population because in real life situations, such environmental change often limits the resources available. Fig. 1A shows results from two populations: one with a broad distribution of phenotypes and one with a narrow distribution of phenotypes. Multiple runs of this model illustrate that populations with a broad phenotypic distribution are more likely to persist following a random change in selective pressures, whereas those with a narrow phenotypic distribution frequently go extinct under similar circumstances (Fig. 1B,C).

As this model illustrates, the proportion of a population that survives selection is a critical parameter, especially for small populations. Following the initial selection of phenotypes, sexual reproduction generates new combinations of genes which contribute to the expression of novel phenotypes in the altered environment, some of which may have high fitness. But if the environment changes faster than the population can behaviorally or otherwise adapt, it may quickly go extinct, regardless of how much genetic variation is present. Since we rarely foresee how environmental conditions will change, predicting shifts in the relative fitness of different phenotypes is problematic. Preserving a broad range of phenotypes could thus prevent a significant decline in the population.

\section{Phenotypes and reproductive success}

A critical concern to conservation biologists is to preserve the reproductive capacity of endangered populations by maintaining a high number of reproductive individuals (i.e. large effective population size, $N_{\mathrm{e}}$; Hedrick and Kalinowski, 2000). One way to do this is to identify factors that contribute to variation in reproductive success for the population in question. Theoretic studies suggest that when variance in reproductive success among individuals in a population is high, $N_{\mathrm{e}}$ drops below the total population size (Fig. 2; Nunney, 1993; Hedgecock, 1994; Parker and Waite, 1997). Here, only a few individuals are monopolizing reproduction. In threatened or endangered populations that are already small, restoration efforts that increase the variance in reproductive success can push $N_{\mathrm{e}}$ even lower, causing further loss of genetic diversity. Under these conditions, it is particularly important to identify environmental factors that affect variation in reproductive success among members of a population.

For example, in most species the variation in reproductive success is higher among males than females (e.g. Andersson, 1994). This variation occurs because some males have a greater ability than other males to defend females or the resources needed to reproduce successfully

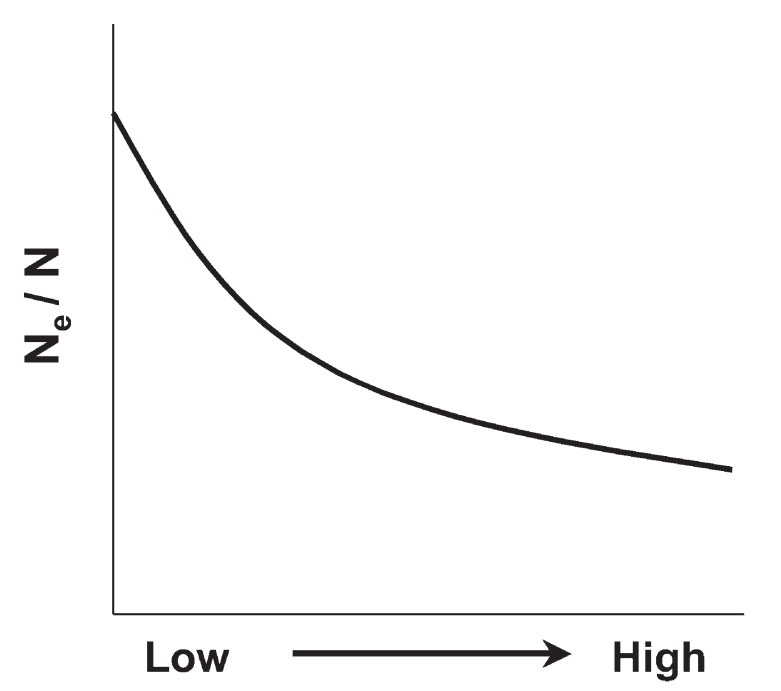

Variance in Male Reproductive Success

Fig. 2. Relationship between the variance in male reproductive success in a population and that population's effective size $\left(N_{\mathrm{e}}\right)$. Adapted from Parker and Waite (1997).

(Taborsky, 2001). For example, in the African cichlid Lamprologus callipterus, females lay their eggs in the empty shells of gastropods. Males of this species collect the shells in a nest and defend their nest against other males. Larger males are able to gather and defend more shells than smaller males, and thus acquire more matings (Sato, 1994). This difference in the ability to horde shells creates a high variance in male reproductive success.

In other fishes, including many species threatened with extinction, males express alternative reproductive phenotypes (Table 1). These alternative reproductive phenotypes vary in morphological, behavioral, or life history characteristics (for review, see Taborsky, 1994) and can decrease the variance in reproductive success among males (Jones et al., 2001). For example, in the sand goby (Pomatoschistus minutus), some males establish and control nests where females lay their eggs, while other males attain mates by sneaking into these nests. Genetic analyses have shown that a high percentage of nests contain eggs fertilized by males other than the owner (Jones et al., 2001). Thus, sneaking into the nest is a successful tactic that decreases the variation in reproductive success among males.

In most published examples, the expression of alternative reproductive phenotypes depends on the social and environmental conditions that an individual experiences during development (for review, see Gross, 1996). A number of studies have examined how specific ecological factors alter the expression of reproductive phenotypes within populations. For example, density (Kodric-Brown, 1986; Kodric-Brown, 1988a), the sex ratio of conspecifics (Kodric-Brown, 1988b; Carroll and Corneli, 1995) and the distribution of male body size (Danylchuk and Tonn, 2001) can influence the expression 
Table 1

Imperiled fishes with variation in male reproductive phenotypes

\begin{tabular}{lllll}
\hline Taxon & $\begin{array}{l}\text { Description of alternative } \\
\text { reproductive phenotype }\end{array}$ & $\begin{array}{l}\text { Reversibility } \\
\text { of phenotype }\end{array}$ & $\begin{array}{l}\text { Resources that may } \\
\text { influence phenotypic } \\
\text { expression }\end{array}$ & Reference
\end{tabular}

\section{Catostomidae}

Moxostoma erythrurum ${ }^{\text {a }}$

(golden redhorse)

\section{Cyprinidae $^{\mathrm{b}}$}

Nocomis micropogon

(river chub)

Semotilus corporalis

(fallfish minnow)

\section{Cyprinodontidae}

Cyprinodon macularius

(desert pupfish)

Cyprinodon nevadensis mionectes

(Ash Meadows pupfish)

Cyprinodon nevadensis pectoralis

(Warm Springs pupfish)

Cyprinodon pecosensis

(Pecos pupfish)

\section{Percidae}

Etheostoma nigrum ${ }^{\text {a }}$

(johnny darter)

Etheostoma perlongum

(Waccamaw darter)

\section{Poeciliidae}

Poeciliopsis occidentalis occidentalis (Gila topminnow)

\section{Salmonidae}

Oncorhynchus keta

(chum salmon)

Oncorhynchus kisutch

(coho salmon)

Oncorhynchus tshawytscha

(Chinook salmon)

Salmo salar

(Atlantic salmon)

Thymallus arcticus

(Arctic grayling)

Territorials, sneakers

Reversible

Distribution of shallow shoals and deep pools

Resident nest-builders, satellites

Territorial nesters, satellites

Territorials, floaters,

sneakers

Territorials, floaters,

sneakers

Dominants, subordinates

Territorials, floaters, sneakers

Territorial nesters,

sneakers

Territorials, sneakers

Territorials, sneakers

Territorials, satellites

Early-maturing,

late-maturing

Early-maturing,

late-maturing

Early-maturing,

late-maturing

Territorials, floaters
Reversible (?)

Reversible gravel substrate (?)

Presence of communal

nesting sites (?)

Reversible
Reversible
Reversible
Reversible

Reversible (?)

Reversible (?)

Reversible (?) Food resources for juveniles,

Reversible (?) Availability of spawning

Irreversible

Irreversible

Irreversible

Reversible (?) rocks

Food resources during

juvenile life stages (?) population demography (?)

substrate

Heterogeneous, spawning

Heterogeneous, spawning

substrate

Heterogeneous, spawning substrate

Distribution of shallow riffles

for juvenile foraging

Distribution of shallow riffles

for juvenile foraging

Distribution of shallow riffles

for juvenile foraging

Availability of spawning

substrate
(Kwak and Skelly, 1992)

(Sabaj et al., 2000)

(Ross, 1983)

(Barlow, 1961)

(Soltz, 1974)

(Soltz, 1974)

(Kodric-Brown, 1978)

(Winn, 1958)

(Shute et al., 1982)

(Constantz, 1975)

(Schroder, 1982)

(Gross, 1985)

(Foote et al., 1991)

(Jones and King, 1952)

(Klatt and Smith, 1980)

a Although many populations of the taxon are stable, some populations or subspecies of the taxon require protection with endangered, threatened, or special status.

b Species listed here under family Cyprinidae are currently stable, although numerous other species within this taxon require protection with endangered, threatened, or special status.

of reproductive phenotypes. Unfortunately, directly manipulating many of these factors in a management context is untenable. For example, selectively removing individuals from a population might be detrimental if the density is already low. Other factors, however, are more accessible to conservation efforts. We and others have suggested that changing the distribution of resources leads to a cascade of effects which can influence the demographics of populations with predictable outcomes (e.g. Kokko et al., 2001; Watters and Nevitt, unpublished data). Because resources are easy to manipulate and influence population demographics, we will focus our discussion on structuring habitats to manage phenotypic variation.

\section{Structuring habitats to manage phenotypes: experimental approaches}

Identifying how environmental factors affect the development and reproductive success of individuals in a population is a formidable task, but much headway 
can be made with simple experimental approaches. Here we discuss how the management of phenotypes might inform efforts to preserve two endangered taxa which span the spectrum of conservation challenges: Pacific salmon (Oncorhynchus spp.) and desert pupfishes (Cyprinodon spp.). The cultural and economic importance of Pacific salmon drives significant financial support for conservation efforts, even in the face of only minor successes. For pupfish, apathy and the increased use of aquifers have hindered efforts to preserve the many endemic populations in the southwestern deserts of North America (Pister, 1993). Both species show discrete variation in male reproductive phenotypes. These alternative phenotypes are "condition-dependent": their frequency in a population depends on the distribution of resources in the environment. Because the premise of phenotype management is to use resources to manage phenotypes, salmon and pupfish provide clear examples of how phenotype management can be used in real life situations.

\subsection{Pacific salmon}

Populations of Pacific salmon (Oncorhynchus spp.) have severely declined throughout their native range. There are several causes for these declines, but the alteration of freshwater habitats is frequently cited as a leading contributing factor, especially in the southern portion of their range (e.g. Brown et al., 1994; Yoshiyama et al., 1998; Levin and Schiewe, 2001). Freshwater salmon habitats have been severely degraded by many land-use practices. Mining, timber harvesting, and farming alter water flows and increase sediment run-off. Dams block the down- and up-river migrations of salmon moving between their natal streams and the ocean.

The efforts to conserve salmon are as diverse as the causes of their decline. Each year, millions of salmon are produced in hatcheries to supplement wild populations. Juveniles attempting to migrate from their natal streams to the ocean are rerouted through bypasses, or even shuttled around barriers in barges. These efforts have been partially successful, but require constant "hands-on" labor in order to work. In many cases, the rehabilitation of freshwater habitats may be the only way to restore self-sustaining populations of salmon.

Freshwater habitat directs juvenile growth and the expression of phenotypes in salmon (for review, see Metcalfe, 1998). The males of many species exhibit alternative reproductive phenotypes that differ in age at maturity (Groot and Margolis, 1991). In coho salmon (Oncorhynchus kisutch), for example, males develop into either a large hooknose or a small jack reproductive phenotype (Fig. 3A). Once an individual adopts either a hooknose or jack phenotype, the developmental trajectory cannot be reversed. This trajectory is based on an individual's body condition - a parameter intimately tied to juvenile growth rates in freshwater streams. Small juvenile males mature as hooknoses. They spend $1 \frac{1}{2}-2$ years in the ocean, become sexually mature at $2 \frac{1}{2}-$ 3 years of age, and fight for access to females in the spawning streams. In contrast, juvenile males who attain the largest sizes in freshwater habitat tend to mature early as jacks. These fish return to spawn one year earlier than hooknoses. Jacks do not fight for access to females but hide to avoid conflicts with hooknosed males. Jacks spawn by darting into a female's nest (redd) during oviposition.

Though jacks are often overlooked, the occurrence of alternative male phenotypes in a salmon population is critical to consider in developing conservation strategies. Jacks insure that a particular cohort will persist despite unfavourable conditions in the ocean or in spawning streams. Because these fish spend significantly less time than hooknoses in the ocean, stochastic changes in the ocean environment are less likely to eliminate an entire cohort if that cohort expresses both jack and hooknose phenotypes. Similarly, if freshwater spawning conditions are poor in a particular year, some members of a cohort may still reproduce successfully in an alternative year. In addition, because jacks spawn in a different year than hooknoses of their cohort, jacking allows regular genetic exchange between generations to increase the $N_{\mathrm{e}}$ of the population (Nunney, 1993). These key concerns are overshadowed by the economic and popular appeal of big fish, but clearly jacks are critical players in maintaining healthy populations over the long term.

With respect to phenotype management, recent experimental evidence suggests that the structural conditions of a juvenile habitat influence the frequency of early sexual maturation in coho salmon (Watters and Nevitt, unpublished data). In wild streams, juveniles tend to occupy either riffles or pools. We simulated these habitat types in the laboratory and followed the growth rates of tagged individuals until sexual maturation. We found that the riffle treatment promoted greater variation both in growth rates and in the timing of sexual maturation as compared to the pool treatment. Juveniles reared in the riffle treatment were more likely to mature as jacks than those reared in the pool treatment (Table 2).

The results of these experiments are compelling in suggesting that habitat restoration may also influence growth rate and the expression of alternative male phenotypes in natural populations. An idea that needs to be further explored is that the quality of juvenile feeding territories in the wild will affect the probability of early maturation by influencing growth rates (see also Metcalfe, 1998). Juvenile salmon feed mostly on insect larvae adrift in the stream current. In pools, water flows uniformly, and drifting food is distributed throughout 

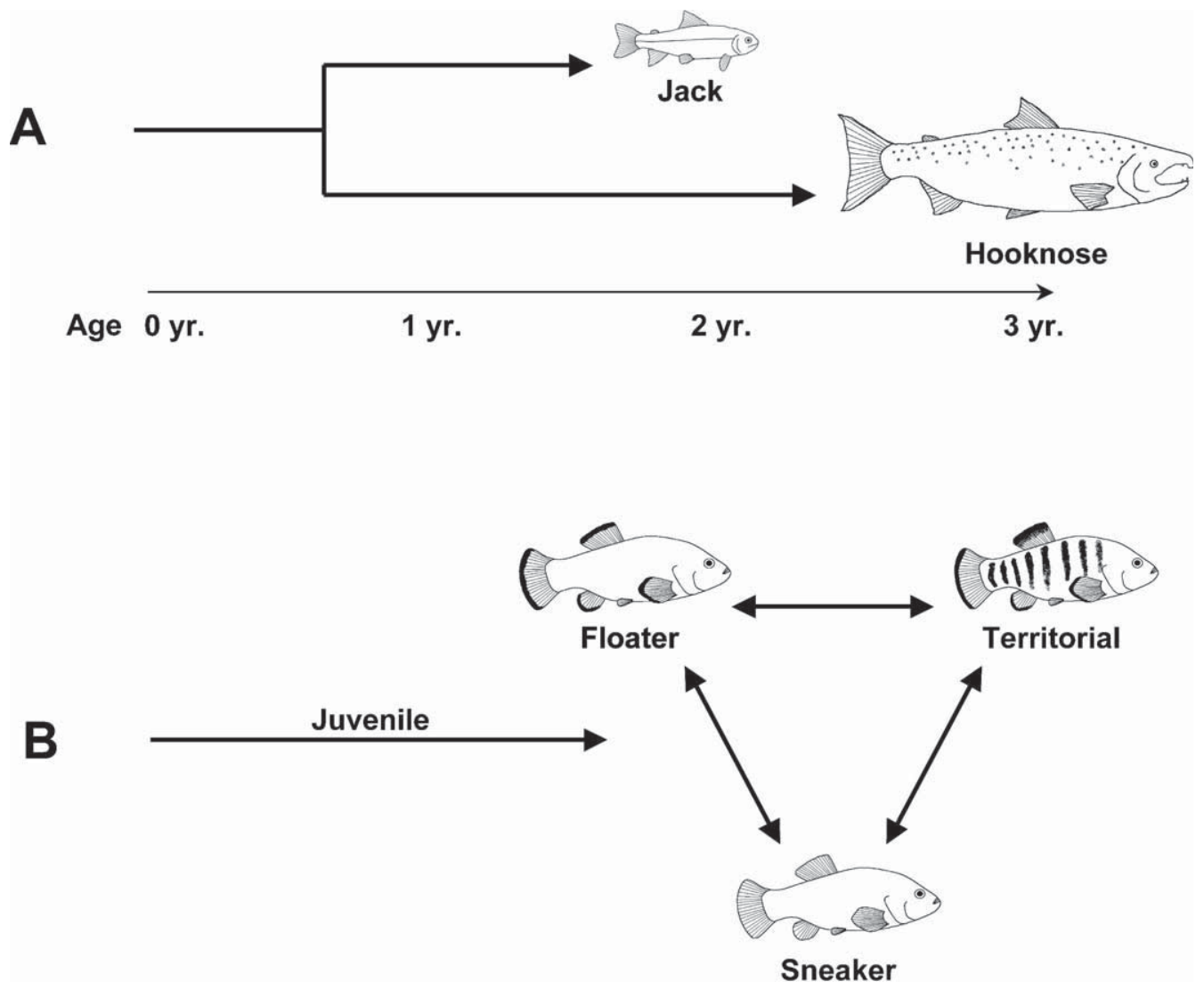

Fig. 3. Alternative reproductive phenotypes in males of (A) coho salmon, Oncorhynchus kisutch, and (B) pupfish, Cyprinodon spp. Male coho salmon exhibit either an early-maturing jack or a late-maturing hooknose phenotype (A: adapted from Gross, 1985) that are irreversible following early development. Pupfish males may repeatedly switch between a territorial, floater, or sneaker phenotype throughout their life (B).

the entire pool-reach. Because resources are not defendable, individuals should grow at similar rates. However, in riffles, water flow is turbulent and food is unevenly channeled through the riffle-reach. This uneven distribution of food may allow some juveniles to establish foraging territories and grow more quickly than those that cannot (Fausch, 1984; Sloman et al., 2000). While the link between territoriality and growth rate has not been rigorously established, our data clearly indicates that rapidly growing fish are more likely to mature early as jacks (Watters and Nevitt, unpublished data).

If a higher proportion of jacks are produced in riffles than in pools under natural circumstances, it should be

\section{Table 2}

Incidence of early sexual maturation (jacking) in Oncorhynchus kisutch reared in two replicate tanks of the 'pool' and 'riffle' treatments

\begin{tabular}{lccccc}
\hline & \multicolumn{2}{c}{ 'Pool' treatment } & & 'Riffle' treatment \\
\cline { 2 - 3 } \cline { 6 - 7 } & Tank 1 & Tank 2 & & Tank 1 & Tank 2 \\
\hline $\begin{array}{l}\text { No. jacks/no. total males } \\
\text { \% Jacks }\end{array}$ & $0 / 14$ & $1 / 18$ & & $2 / 14$ & $3 / 15$ \\
\hline
\end{tabular}

possible to shift the frequency of jacks and hooknoses in a population by altering the proportion of these two reaches within a stream. In support of this idea, it has been shown that creeks with a higher riffle:pool ratio produce more fast-growing juveniles (Nislow et al., 1999). Logically, we might expect a higher proportion of early-maturing males in these creeks than in those with low riffle:pool ratios. Clearly habitat variation in a watershed generates phenotypic diversity among juvenile salmon. How we choose to restore a salmon stream will affect that diversity and is a valuable topic of research for conservation management.

\subsection{Desert pupfishes}

Pupfishes (Cyprinodon spp.) of southwestern North America occupy aquatic habitats isolated by the surrounding desert. These habitats are diverse and range from small, freshwater springs to intermittent, saline streams. Dams and diversions to support irrigation, flood control projects, and extensive ground water pumping have modified permanent water sources in the desert. These modifications have already caused the decline and extinction of many populations of pupfish, 
and most of the remaining populations are in danger of extinction (Minckley et al., 1991b). Efforts to conserve the remaining populations have included propagating fish in captivity (Johnson and Jensen, 1991) and constructing artificial refugia (Baugh and Deacon, 1988; Winemiller and Anderson, 1997). While these approaches have had limited success, the only long-term solution may be to rehabilitate altered habitats (Soltz and Naiman, 1978).

Pupfish have generally been categorized into three reproductive phenotypes: (1) a territorial phenotype, (2) a floater or satellite phenotype, and (3) a sneaker phenotype (Fig. 3B: Barlow, 1961; Soltz, 1974; KodricBrown, 1986). These phenotypes are flexible, and an individual may change between them many times during his lifetime depending on the current ecological conditions (Kodric-Brown, 1986, 1988a,b). Territorial males are deep blue, and defend an area of the substrate from intrusions by other males (Barlow, 1961; Soltz, 1974; Kodric-Brown, 1977). Laboratory experiments have shown that territorial males have a higher reproductive success than the other phenotypes (Kodric-Brown, 1986). Like territorial males, floater males are also pigmented blue. These fish do not defend a territory; instead, they cruise between the territories of other males or hover in the water column above another male's territory. Floater males spawn with females while territorial males are engaged in agonistic behaviors or spawning in a different location on the territory. Finally, the "sneaker" phenotype retains the cryptic, brown coloration of juveniles. Sneakers reside in mixed groups with females and juveniles in areas of the habitat that are not being used for reproduction. These males spawn surreptitiously, either in a group with a female and a territorial or floater male, or alone with a female when territorial males are otherwise engaged (KodricBrown, 1986).

Pupfish males establish reproductive territories over substrates composed of rocky embankments, dense algal clumps, and sandy bottoms with rocks and plant debris (Barlow, 1961; Soltz, 1974; Kodric-Brown, 1977, 1978). Exposed, rocky substrates are the favored oviposition sites for female pupfish (Ludlow et al., 2001). They spawn less frequently on homogeneous substrates such as sand or silt. As a result, males that occupy territories over rocky, heterogeneous substrates have a significantly higher reproductive success than males holding territories over the bare, sandy bottom (KodricBrown, 1977; Ludlow et al., 2001). Field studies of the Pecos pupfish, Cyprinodon pecosensis, have shown that the largest males occupy territories over topographically heterogeneous areas of the substrate (Kodric-Brown, 1977, 1978). The territories of these large males contain considerable amounts of exposed rock with scattered algal patches comprising a significant proportion of the territory area. Smaller males are relegated to territories with a higher proportion of bare sandy regions. Floaters favor the territories of males with the highest spawning rates (Kodric-Brown, 1986).
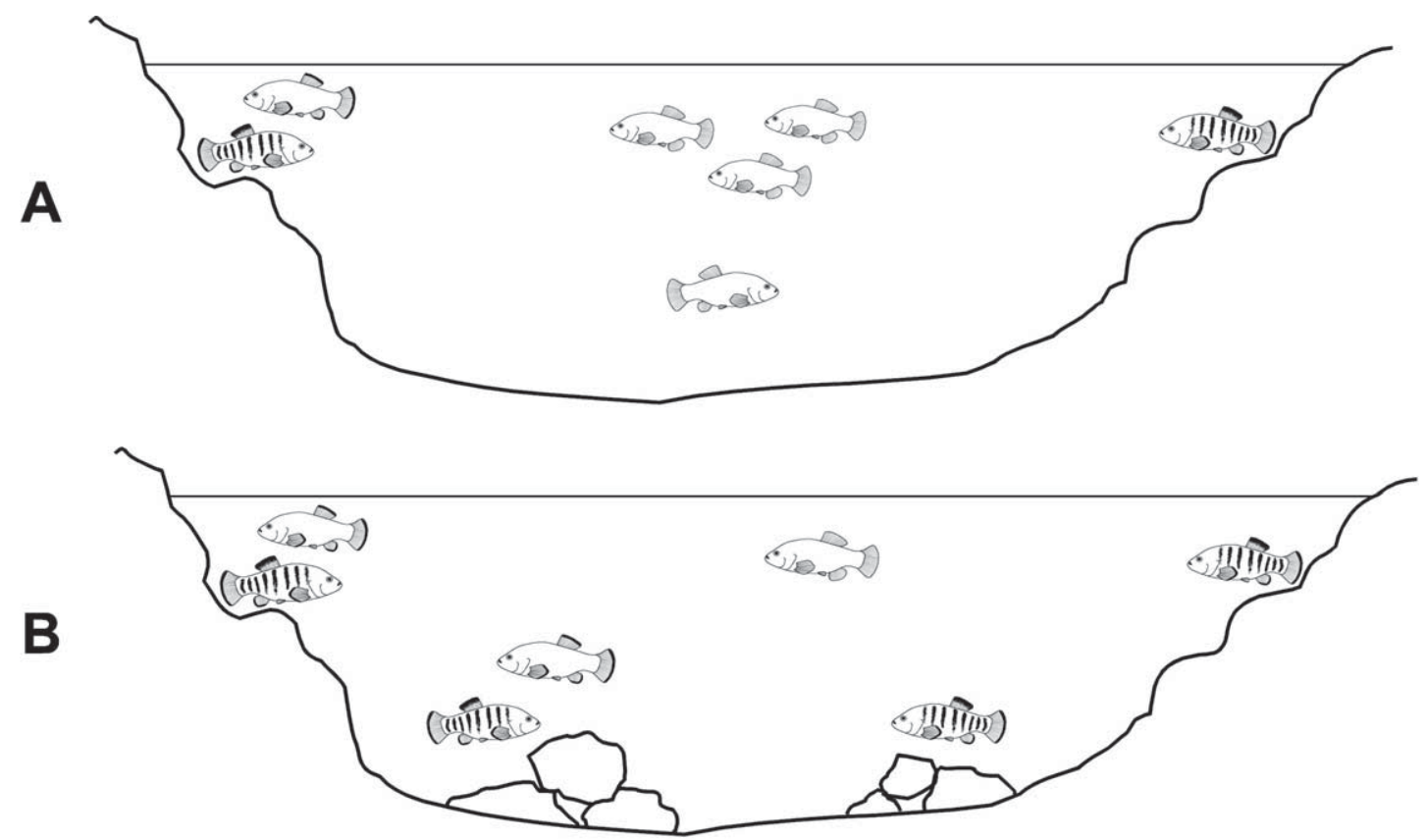

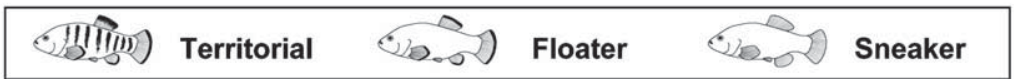

Fig. 4. Habitat structure modulates pupfish reproductive phenotypes. (A) A pupfish population may contain only a few territorial males due to the limited availability of reproductive substrate. (B) Adding rocks can increase the proportion of substrate that is suitable for reproduction, and induce previously non-territorial males to establish reproductive territories. 


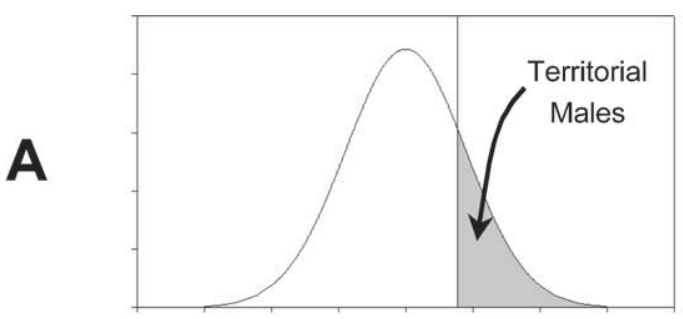

Body Size

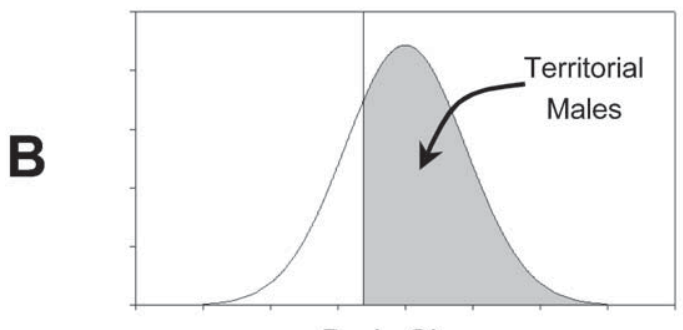

Body Size
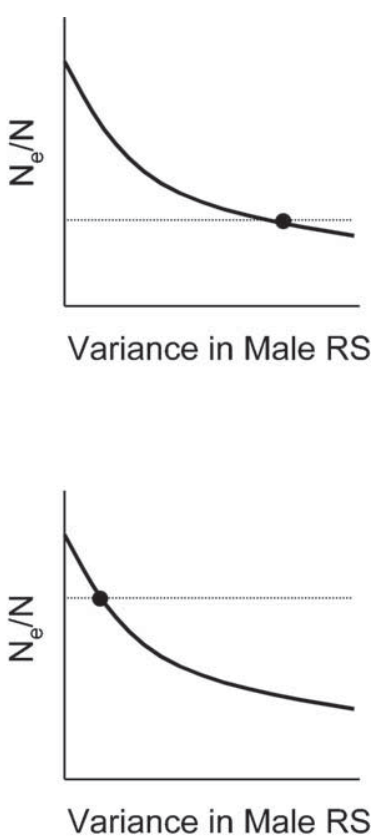

Fig. 5. Phenotypic distribution of male pupfish in a habitat undergoing a change in the availability of spawning substrate. The population's body size distribution does not change when a habitat with (A) little spawning substrate is altered to create a (B) higher availability of spawning substrate, even though the proportion of males that defend reproductive territories changes between habitats. This rise in the number of territorial males shifts the variance in male reproductive success (RS) and increases the population's effective size $\left(N_{\mathrm{e}}\right)$ relative to overall population size $(N)$.

There is evidence that changing the physical structure of a habitat by altering the number and quality of available territories can influence the allocation of spawnings among males in a population. Kodric-Brown (1978) showed that changing the availability of heterogeneous substrate alters the number of territorial males in a wild population of $C$. pecosensis. Introducing large rocks onto bare, sandy areas of habitat induced previously non-territorial males to establish reproductive territories over the rocks. The repeated introduction and removal of the same rocks into different parts of a habitat resulted in fish establishing territories of similar size and location over each rock. These results suggest that the distribution and number of territorial pupfish males in a population is dependent on the physical characteristics of the environment.

Given that the physical structure of a habitat drives individuals to adopt particular reproductive phenotypes, we should consider constructing habitats to achieve explicit frequencies of these phenotypes. Here the mechanism is behavioral: if more males defend reproductive territories, then reproductive success will be distributed more evenly among males in the population. As Fig. 4 illustrates, we can increase the number of territorial males by increasing the proportion of heterogeneous substrate in a habitat. These manipulations should decrease the variance of reproductive success among males because more males should hold territories over the type of spawning substrate that is preferred by females. This simple manipulation thus leads to a more even allocation of spawnings among males, because a small proportion of the largest males can no longer monopolize the preferred substrate for oviposition. Fig. 5 further illustrates that we may be able to alter $N_{\mathrm{e}}$ simply by increasing the number of territorial males in a population. The ability to maintain a high $N_{\mathrm{e}}$ is significant given that desert pupfish often occur in small and isolated populations which show little genetic diversity (Meffe and Vrijenhoek, 1988; Echelle and Dowling, 1992; Duvernell and Turner, 1998, 1999).

\section{Conclusion}

The fundamental goal of any restoration project is to replenish the resources that are necessary for the successful survival and reproduction of the target population. Previous restoration approaches have aimed at restoring resources but have given little consideration to how resource distributions affect the demography of target populations. With phenotype management we go a step further and consider how the distribution and quality of resources within a habitat shape the expression of phenotypes.

Our discussion has focused on salmon and pupfish. With salmon, we have emphasized how habitat structure influences food distribution and subsequent growth and timing of sexual maturation; with pupfish we have illustrated how altering spawning habitat shapes the allocation of reproductive success. To apply phenotype management to other species, a first step is to identify a critical resource that affects the expression of phenotypic 
traits for the target species. For reproductive phenotypes, it might be the availability of high quality breeding territories or nesting sites. For other phenotypic traits, it might be the abundance of a particular type of food (Day et al., 1994; Mittelbach et al., 1999) or the regularity of predators in a habitat (van Buskirk and McCollum, 2000). We can alter the ability of individuals to utilize a resource by creating temporal or spatial variation in its distribution and quality. When resources vary across a habitat, individuals relying on those resources may express different phenotypes. Using this approach, we can engineer the resource distribution to achieve a particular demography or $N_{\mathrm{e}}$ for a population, and increase the likelihood that the population will persist for the future.

\section{Acknowledgements}

This work was supported by the Sonoma County Water Agency, NIH (PHS DCO3174) and NSF (Graduate Research Fellowship to S.C.L). The comments of J.L. Conrad, D. Hedgecock, R. Kihslinger, P. Moyle, J. Trexler, R. van Buskirk and an anonymous reviewer greatly improved the quality of this manuscript.

\section{References}

Andersson, M., 1994. Sexual Selection. Princeton University Press, Princeton, NJ.

Barlow, G.W., 1961. Social behavior of the desert pupfish, Cyprinodon macularius, in the field and in the aquarium. American Midland Naturalist 65, 339-359.

Baugh, T.M., Deacon, J.E., 1988. Evaluation of the role of refugia in conservation efforts for the Devil's Hole pupfish Cyprinodon diabolis Wales. Zoo Biology 7, 351-358.

Boag, P.T., Grant, P.R., 1981. Intense natural selection in a population of Darwin's finches (Geospizinae) in the Galápagos. Science $214,82-85$.

Brown, J.I., 1964. The evolution of diversity in avian territorial systems. The Wilson Bulletin 76, 160-169.

Brown, L.R., Moyle, P.B., Yoshiyama, R.M., 1994. Historical decline and current status of coho salmon in California. North American Journal of Fisheries Management 14, 237-261.

Carroll, S.P., Corneli, P.S., 1995. Divergence in male mating tactics between two populations of the soapberry bug: II. Genetic change and the evolution of a plastic reaction norm in a variable social environment. Behavioral Ecology 6, 46-56.

Constantz, G.D., 1975. Behavioral ecology of mating in the male Gila topminnow, Poeciliopsis occidentalis (Cyprinodontiformes: Poeciliidae). Ecology 56, 966-973.

Danylchuk, A.J., Tonn, W.M., 2001. Effects of social structure on reproductive activity in male fathead minnows (Pimephales promelas). Behavioral Ecology 12, 482-489.

Day, T., Pritchard, J., Schulter, D., 1994. A comparison of two sticklebacks. Evolution 48, 1723-1734.

Duvernell, D.D., Turner, B.J., 1999. Variation and divergence of Death Valley pupfish populations at retrotransponson-defined loci. Molecular Biology and Evolution 16, 363-371.

Duvernell, D.D., Turner, B.T., 1998. Evolutionary genetics of Death Valley pupfish populations: mitochondrial DNA sequence variation and population structure. Molecular Ecology 7, 279-288.
Echelle, A.A., Dowling, T.E., 1992. Mitochondrial DNA variation and evolution of the Death Valley pupfishes (Cyprinodon, Cyprinodontidae). Evolution 46, 193-206.

Endler, J.A., 1986. Natural Selection in The Wild. Princeton University Press, Princeton NJ.

Fausch, K.D., 1984. Profitable stream positions for salmonids: relating specific growth rate to net energy gain. Canadian Journal of Zoology 62, 441-451.

Flosi, G., Downie, S., Hopelain, J., Bird, M., Coey, R., Collins, B., 1998. California Salmonid Stream Habitat Restoration Manual. State of California Resources Agency, California Department of Fish and Game, California.

Foote, C., Clarke, W.C., Blackburn, J., 1991. Inhibition of smolting in precocious male chinook salmon, Oncorhynchus tshawytscha. Canadian Journal of Zoology 69, 1848-1852.

Groot, C., Margolis, L., 1991. Pacific Salmon Life Histories. University of British Columbia, Vancouver, BC.

Gross, M.R., 1985. Disruptive selection for alternative life histories in salmon. Nature 313, 47-48.

Gross, M.R., 1996. Alternative reproductive strategies and tactics: Diversity within sexes. Trends in Ecology and Evolution 11, 92-98.

Hedgecock, D., 1994. Does variance in reproductive success limit effective population sizes of marine organisms? In: Beaumont, A.R. (Ed.), Genetics and Evolution of Aquatic Organisms. Chapman and Hall, London, UK, pp. 122-134.

Hedrick, P.W., Kalinowski, S.T., 2000. Inbreeding depression in conservation biology. Annual Review of Ecology and Systematics 31, 139-162.

Jenkins, R.E., Burkhead, N.M., 1984. Description, biology and distribution of the spotfin chub, Hybopsis monacha, a threatened cyprinid fish of the Tennessee River drainage. Bulletin of the Alabama Museum of Natural History 8, 1-30.

Johnson, J.E., Jensen, B.L., 1991. Hatcheries for endangered freshwater fishes. In: Minckley, W.L., Deacon, J.E. (Eds.), Battle Against Extinction: Native Fish Management in the American West. University of Arizona Press, Tuscon, AZ, pp. 199-217.

Johnston, C.E., 1999. The relationship of spawning mode to conservation of North American minnows (Cyprinidae). Environmental Biology of Fishes 55, 21-30.

Jones, A.G., Walker, D., Kvarnemo, C., Lindström, K., Avise, J.C., 2001. How cuckoldry can decrease the opportunity for sexual selection: data and theory from a genetic parentage analysis of the sand goby, Pomatoschistus minutes. Proceedings of the National Academy of Sciences, USA 98, 9151-9156.

Jones, J.W., King, G.M., 1952. The spawning of the male salmon parr (Salmo salar Linn. juv.). Proceedings of the Zoological Society of London 122, 615-619.

Klatt, L.F., Smith, R.J.F., 1980. An analysis of the spawning behaviour of the Arctic grayling Thymallus arcticus (Pallus) with observations on mating success. Journal of Fish Biology 17, 661-666.

Kodric-Brown, A., 1977. Reproductive success and the evolution of breeding territories in pupfish (Cyprinodon). Evolution 31, 750-766.

Kodric-Brown, A., 1978. Establishment and defense of breeding territories in a pupfish (Cyprinodontidae: Cyprinodon). Animal Behaviour 26, 818-834.

Kodric-Brown, A., 1986. Satellites and sneakers: Opportunistic male breeding tactics in pupfish (Cyprinodon pecosensis). Behavioral Ecology and Sociobiology 19, 425-432.

Kodric-Brown, A., 1988a. Effect of population density, size of habitat and oviposition substrate on the breeding system of pupfish (Cyprinodon pecosensis). Ethology 77, 28-43.

Kodric-Brown, A., 1988b. Effects of sex-ratio manipulation on territoriality and spawning success of male pupfish, Cyprinodon pecosensis. Animal Behaviour 36, 1136-1144.

Kokko, H., Sutherland, W.J., Johnstone, R.A., 2001. The logic of territory choice: implications for conservation and source-sink dynamics. American Naturalist 157, 459-463. 
Kwak, T.J., Skelly, T.M., 1992. Spawning habitat, behavior, and morphology as isolating mechanisms of the golden redhorse, Moxostoma erythrurum, and the black redhorse, $M$. duquesnei, two syntopic fishes. Environmental Biology of Fishes 34, 127-137.

Levin, P.S., Schiewe, M.H., 2001. Preserving salmon biodiversity. American Scientist 89, 220-227.

Ludlow, A.M., Itzkowitz, M., Baird, D.R., 2001. Male mating success and female preference for multiple traits in the twoline pupfish (Cyprinodon bifasciatus). Behaviour 138, 1303-1318.

MacLean, A., Metcalfe, N.B., Mitchell, D., 2000. Alternative competitive strategies in juvenile Atlantic salmon (Salmo salar): evidence from fin damage. Aquaculture 184, 291-302.

Meffe, G.K., Vrijenhoek, R.C., 1988. Conservation genetics in the management of desert fishes. Conservation Biology 2, 157-169.

Metcalfe, N.B., 1998. The interaction between behavior and physiology in determining life history patterns in Atlantic salmon (Salmo salar). Canadian Journal of Fisheries and Aquatic Sciences 55 (Suppl. 1), 93-103.

Metcalfe, N.B., Thorpe, J.E., 1992. Early predictors of life-history events: the link between first feeding date, dominance and seaward migration in Atlantic salmon Salmo salar L. Journal of Fish Biology 41 (Suppl. B), 93-99.

Meyer, A., 1987. Phenotypic plasticity and heterochrony in Cichlasoma managuense (Pisces, Cichlidae) and their implications for speciation in cichlid fishes. Evolution 41, 1357-1369.

Minckley, W.L., Deacon, J.E., 1991. Battle against Extinction: Native Fish Management in the American West. University of Arizona Press, Tucson, AZ

Minckley, W.L., Marsh, P.C., Brooks, J.E., Johnson, J.E., Jensen, B.L., 1991a. Management toward recovery of the razorback sucker. In: Minckley, W.L., Deacon, J.E. (Eds.), Battle Against Extinction: Native Fish Management in the American West. University of Arizona Press, Tucson, AZ, pp. 303-357.

Minckley, W.L., Meffe, G.K., Soltz, D.L., 1991b. Conservation and management of short-lived fishes: The cyprinodontoids. In: Minckley, W.L., Deacon, J.E. (Eds.), Battle Against Extinction: Native Fish Management in the American West. University of Arizona Press, Tucson, AZ, pp. 303-357.

Mittelbach, G.G., Osenberg, C.W., Wainwright, P.C., 1992. Variation in resource abundance affects diet and feeding morphology in the pumpkinseed sunfish (Lepomis gibbosus). Oecologia 90, 8-13.

Mittelbach, G.G., Osenberg, C.W., Wainwright, P.C., 1999. Variation in feeding morphology between pumpkinseed populations: phenotypic plasticity or evolution? Evolutionary Ecology Research 1, 111-128.

Moyle, P.B., 1976. Some effects of channelization on fishes and invertebrates of rush creek, Modoc county, California. California Fish and Game 62, 179-186.

Moyle, P.B., 1994. The decline of anadromous fishes in California. Conservation Biology 8, 869-870.

Neves, R.J., Angermeier, P.L., 1990. Habitat alteration and its effects on native fishes in the upper Tennessee river system, east-central U.S.A.. Journal of Fish Biology 57 (Suppl. A), 45-52.

Nielsen, J.L., 1992. Microhabitat-specific foraging behavior, diet, and growth of juvenile coho salmon. Transactions of the American Fisheries Society 121, 617-634.

Nislow, K.H., Folt, C.L., Parrish, D.L., 1999. Favorable foraging locations for young Atlantic salmon: application to habitat and population restoration. Ecological Applications 9, 1085-1099.

Nunney, L., 1993. The influence of mating system and overlapping generations on effective population size. Evolution 47, 1329-1341.

Parker, P.G., Waite, T.A., 1997. Mating systems, effective population size, and conservation of natural populations. In: Clemmons, J.R., Buchholz, R. (Eds.), Behavioral Approaches to Conservation in the Wild. Cambridge University Press, Cambridge, UK, p. 382.

Pister, E.P., 1993. Species in a bucket. Natural History 14, 14-19.

Puckett, K.J., Dill, L.M., 1985. The energetics of feeding territoriality in juvenile coho salmon (Oncorhynchus kisutch). Behaviour 92, 97-111.
Rodd, F.H., Sokolowski, M.B., 1995. Complex origins of variation in the sexual behaviour of male Trinidadian guppies, Poecilia reticulata: interactions between social environment, heredity, body size and age. Animal Behaviour 49, 1139-1159.

Ross, M.R., 1983. The frequency of nest construction and satellite male behavior in the fallfish minnow. Environmental Biology of Fishes 9, 65-70.

Ryer, C.H., Olla, B.L., 1995. The influence of food distribution upon the development of aggressive and competitive behaviour in juvenile chum salmon, Oncorhynchus keta. Journal of Fish Biology 46, 264-272.

Sabaj, M.H., Maurakis, E.G., Woolcott, W.S., 2000. Spawning behaviors in the bluehead chub, Nocomis leptocephalus, river chub, $N$. micropogon and central stoneroller, Campostoma anomalum. American Midland Naturalist 144, 187-201.

Sato, T., 1994. Active accumulation of spawning substrate: a determinant of extreme polygyny in a shell-brooding cichlid fish. Animal Behaviour 48, 669-678.

Schroder, S.L., 1982. The influence of intrasexual competition on the distribution of chum salmon in an experimental stream. In: Brannon, E.L., Salo, E.O. (Eds.), Proceedings of the Salmon and Trout Migratory Behavior Symposium. University of Washington, Seattle, WA, pp. 275-285.

Shute, P.W., Shute, J.R., Lindquist, D.G., 1982. Age, growth and early life history of the Waccamaw darter, Etheostoma perlongum. Copeia 1982, 561-567.

Skülason, S., Snorrason, S.S., Jönsson, B., 1999. Sympatric morphs, populations and speciation in freshwater fish with emphasis on Arctic charr. In: Magurran, A.E., May, R.M. (Eds.), Evolution of Biological Diversity. Oxford University Press, Oxford, UK, pp. 70-92.

Sloman, K.A., Gilmour, K.M., Taylor, A.C., Metcalfe, N.B., 2000. Physiological effects of dominance hierarchies within groups of brown trout, Salmo trutta, held under simulated natural conditions. Fish Physiology and Biochemistry 22, 11-20.

Soltz, D.L., 1974. Variation in Life History and Social Organization of Some Populations of Nevada Pupfish, Cyprinodon nevadensis. PhD dissertation, University of California, Los Angeles.

Soltz, D.L., Naiman, R.J., 1978. The natural history of native fishes in the Death Valley system. Natural History Museum of Los Angeles County. Science Series 30, 1-76.

Taborsky, M., 1994. Sneakers, satellites, and helpers: parasitic and cooperative behavior in fish reproduction. Advances in the Study of Behavior 23, 1-101.

Taborsky, M., 2001. The evolution of bourgeois, parasitic, and cooperative reproductive behaviors in fishes. The Journal of Heredity $92,100-110$.

Trexler, J.C., Travis, J., Trexler, M., 1990. Phenotypic plasticity in the sailfin molly, Poecilia latipinna (Pisces: Poeciliidae): II. Laboratory experiment. Evolution 44, 157-167.

Tyus, H.M., 1991. Ecology and management of Colorado squawfish. In: Minckley, W.L., Deacon, J.E. (Eds.), Battle Against Extinction: Native Fish Management in the American West. University of Arizona Press, Tuscon, AZ, pp. 379-402.

van Buskirk, J., McCollum, S.A., 2000. Functional mechanisms of an inducible defense in tadpoles: morphology and behaviour influence mortality risk from predation. Journal of Evolutionary Biology 13, 336-347.

Winemiller, K.O., Anderson, A.A., 1997. Response of endangered desert fish populations to a constructed refuge. Restoration Ecology 5, 204-213.

Winn, H.F., 1958. Observations on the reproductive habits of darters (Pisces: Percidae). American Midland Naturalist 59, 190-212.

Witte, F., Barel, C.D.N., Hoogerhoud, R.J.C., 1990. Phenotypic plasticity of anatomical structures and its ecomorphological significance. Netherlands Journal of Zoology 40, 278-298.

Yoshiyama, R.M., Fisher, F.W., Moyle, P.B., 1998. Historical abundance and decline of Chinook salmon in the Central Valley region of California. North American Journal of Fisheries Management 18, 487-521. 